\title{
Global connections in a changing world: Romanian and U.S. nurses unite
}

\author{
Mary G. Schaal \\ Thomas Jefferson University \\ Molly A. Rose \\ Thomas Jefferson University \\ Ann Doherty \\ Catholic Medical Missions Board, New York \\ Adriana Vilan \\ Institute de Public Health, Cluj-Napoca, Romania
}

Follow this and additional works at: https://jdc.jefferson.edu/nursfp

Part of the Nursing Commons

Let us know how access to this document benefits you

\section{Recommended Citation}

Schaal, Mary G.; Rose, Molly A.; Doherty, Ann; and Vilan, Adriana, "Global connections in a changing world: Romanian and U.S. nurses unite" (2000). College of Nursing Faculty Papers \& Presentations. Paper 2.

https://jdc.jefferson.edu/nursfp/2

This Article is brought to you for free and open access by the Jefferson Digital Commons. The Jefferson Digital Commons is a service of Thomas Jefferson University's Center for Teaching and Learning (CTL). The Commons is a showcase for Jefferson books and journals, peer-reviewed scholarly publications, unique historical collections from the University archives, and teaching tools. The Jefferson Digital Commons allows researchers and interested readers anywhere in the world to learn about and keep up to date with Jefferson scholarship. This article has been accepted for inclusion in College of Nursing Faculty Papers \& Presentations by an authorized administrator of the Jefferson Digital Commons. For more information, please contact: JeffersonDigitalCommons@jefferson.edu. 


\title{
Global Connections in a Changing World: Romanian and U.S. Nurses Unite
}

\author{
Mary G. Schaal, RN, EdD, and Molly A. Rose, RN, PhD \\ Department of Nursing \\ Thomas Jefferson University College of Health Professions
}

\author{
Ann Doherty, RN, MSN, JD \\ Catholic Medical Missions Board \\ New York \\ Adriana Vilan, RN \\ Institute de Public Health \\ Cluj-Napoca, Romania
}

\begin{abstract}
This article describes an international, interdisciplinary, university partnership project to collaborate with health professionals in the city of Cluj-Napoca, Transylvania, Romania, to improve the health status of Romanian workers. Academic and service-based public health nurses from the United States used the model of community competence in outlining the nursing aspect of the project. This model guided the assessment, objectives, collaborative activities, and the outcome evaluation of the project. The dimensions of the model (e.g., commitment, self-other awareness, articulateness, conflict accommodation, management of relations with larger society, and leadership) were used within the context of the political and social environment of the international community.
\end{abstract}

In 1995, the Department of Nursing of the College of Health Professions of Thomas Jefferson University in Philadelphia, Pennsylvania, collaborated with the Romanian Health Care Partnership in Occupational and Environmental Health. This collaboration was funded by the U.S. Agency for International Development and was designed to improve the health and safety of workers in Cluj-Napoca, Romania, through the mechanism of empowerment of local nurses. The specific nursing goals were to increase the clinical competence of local nurses, to increase local cooperative action between physicians and nurses, and to assist local nurses in assuming a broader role in patient care activities in

Requests for reprints should be sent to Mary G. Schaal, Department of Nursing, Thomas Jefferson University College of Health Professions, Suite 1200, 130 South 9th Street, Philadelphia, PA 19107. E-mail: mary.schaal@mail.tju.edu 
Cluj-Napoca. The community competence model guided the assessment, objectives, collaborative activities, and outcomes of the nursing project.

The U.S. and Romanian partners each developed four teams: occupational and environmental medicine, pulmonary medicine, nurse training, and health informatics. The respective U.S. and Romanian teams collaborated to develop team-specific goals and objectives. The overall goals of the nurse training components of the project were to increase the competency of local nurses in the clinical setting and to increase local interaction between physicians and nurses that could result in local nurses assuming a broader role in patient care activities. The workplan for the nurse training team included an initial assessment site visit to Cluj-Napoca by the U.S. members followed by two training visits, and an assessment and training visit to the United States by the Romanian members.

\section{LOCAL HEALTH CARE SYSTEM}

Romania, with a population of 23 million people, is the second most populous country in Central and Eastern Europe. Romania is unique among Eastern European countries in that it has a large proportion of both young and elderly people as a result of pronatalist policies. In $1990,10.1 \%$ of the population was age 65 or older and $23.5 \%$ of the population was under the age of 15 . Projected Romanian life expectancy at birth in 1994 was 68.8 years for men and 74.8 years for women. The ethnic makeup is $89 \%$ Romanian, $7 \%$ Hungarian, and $4 \%$ other (German, Ukrainian, Serb, Croatian, Russian, Turkish, and Gypsy). Romania broke away from an economically devastating communist regime in 1989 and resumed a democratic system of government with a multiparty system and a market economy (Angiewich, 1996). The primary occupations involve industry (38\%) and agriculture (28\%; World Bank, 1998).

Cluj-Napoca, Romania, the partnership city for the project, is the historic capital of Transylvania. It is both a heavily industrialized city and a university city. The main industries are metal processing, food processing, paper and pulp production, textile and footwear manufacturing, chemical and synthetic fiber production, wood processing, glass and ceramics, and electrotechnics (Ross, 1997).

Health care in Romania is organized and financed by the central government, which is strongly committed to providing access to health services to all citizens at little or no cost. Consuming $5.6 \%$ of the country's gross national product, the Romanian health system is supervised and administered by the Ministry of Health and district governments (World Bank, 1992).

The Romanian Ministry of Health and the World Bank established a list of goals for health reform in the 1990s. These goals included improving primary care, providing greater access to family planning services, improving the safety of the blood supply, placing greater focus on preventive care, and upgrading nurse training (Lakey, Nicholas, Wolf, \& D'Meza Leuner, 1996). Since 1990, the Romanian government has introduced 
moderate health system reforms including better hospital management, elimination of compulsory rural work assignments for physicians, and the creation of private health clinics (World Bank, 1992). A future concern is that these reforms may result in a shortage of physicians and medical services in rural areas.

In 1992, Romania had 54.8 nurses per 10,000 population and 18.3 physicians per 10,000 population. However, there is an overabundance of specialists and a scarcity of primary care physicians. Although Romania has 93.0 hospital beds per 10,000 population, only $70 \%$ of the hospital beds are usable because of neglect and disrepair, resulting in crowded hospital conditions (World Bank, 1992). The Ministry of Health in Romania competes with all other nationally funded agencies for a share of very limited resources. Romanian hospitals receive limited funding, resulting in a scarcity of basic equipment, medications, and disposable items.

Districts are responsible for Romania's 5,000 medical dispensaries, which are the major providers of primary care. The dispensaries are responsible for providing primary patient care and for referring the sickest patients to hospitals. Romanians also have the option of going directly to one of the country's 535 polyclinics that provide similar services and more specialized care.

Cardiovascular diseases are the leading cause of death in Romania, accounting for $51.1 \%$ of all deaths among men and $65.3 \%$ of deaths among women. Over $70 \%$ of Romanian men and $29 \%$ of Romanian women smoke, but the percentage of women is increasing. The next leading causes of death are cancer, respiratory disease, injuries, and digestive diseases. The 1994 infant mortality rate for Romania was 20 per 1,000 live births. Between 1980 and 1989, the maternal death rate was 150 per 100,000 live births. After abortion was legalized in 1989, the maternal death rate fell by half (World Health Organization, 1996). AIDS, hepatitis B, lead poisoning, and tuberculosis are other frequent health problems in Romania.

Frequent environmental health problems in Romania, and in Cluj-Napoca in particular, involve exposure to toxic solvents and airborne irritants among workers in foundries and ceramic plants who do not use gloves or face masks; exposure to lead, asbestos, nitrates, and chlorinated pesticides in the drinking water; and silicosis and tuberculosis among miners and foundry workers.

\section{Romanian Nursing}

Prior to 1976, nursing education in Romania consisted of 12 years of general education followed by 2 to 3 years of nursing education. Between 1976 and 1989 the communist regime closed schools of nursing, psychology, social work, and physiotherapy (Boscom, 1991). Today, nursing education consists primarily of vocational-type high school education and a few post-high-school 3-year nursing programs. Presently, there is no word in the Romanian language for nurse. Nurses are referred to as medical assistants (3-year 
post-high-school nursing graduates) or sisters (high school nursing graduates), but for the purposes of this article, the term nurse will be used to refer to both the U.S. and Romanian partners. Nurses in Cluj-Napoca assume multiple roles such as bedside nursing, sanitarians, laboratory technologists, medical technicians, and public health technicians. They work in hospitals, clinics, physician's offices, the Inspectorate of Public Health, and the Institute for Public Health.

\section{COMMUNITY COMPETENCE MODEL}

In the Romanian-U.S. partnership, public health nurses from the academic setting and from the service setting comprised the U.S. nursing team. Nurses from public health and the hospital setting comprised the Romanian nursing team. Because the U.S. nursing team had indirect background information about the status of health and nursing in Romania, a community health model was used to guide the project. The community competence model is a type of empowerment model that has been used for assessing a geographical or political community (Goeppinger \& Baglioni, 1985).

Community competence is a self-sustaining process of community development. It represents the ability of a community to interact effectively. It has been cited as an important indicator of a community's health (Denham, Quinn, \& Gamble, 1998). Cottrell (1976) defined the competent community as

One in which the various component parts of the community: (1) are able to collaborate effectively in identifying the problems and needs of the community; (2) can achieve a working consensus on goals and priorities; (3) can agree on ways and means to implement the agreed-upon goals; and (4) can collaborate effectively in the required actions. (p. 24)

He also identified the eight essential conditions for community competence as commitment, self-other awareness and clarity of situational definitions, articulateness, effective communication, conflict containment and accommodation, participation, management of relations with larger society, and machinery for facilitating participant interaction and decision making. Goeppinger, Lassiter, and Wilcox (1982) developed the Community Resident Survey as an instrument to assess community competence that can be used to assist communities to identify problems and assets in their community process (Goeppinger \& Baglioni, 1985). Later, the concepts of social support and leadership development were added (Eng \& Parker, 1994; Minkler \& Wallerstein, 1997).

Although the overall goal of the university health partnership was to improve the health of Romanian workers, the nursing aspect of the project began by assessing the preparation, needs, and desires of the Romanian nurses. Using the community competence model in Romania, the U.S. nurses initially collaborated with seven Romanian nurses as nurse colleagues despite the very different cultural and educational backgrounds of the two groups. The community competence model was used as both a pro- 
cess and an outcome framework. Assessing and developing the essential conditions for a competent community was the process portion of the model. Evaluation of the project was also conducted through the community competence model by assessing the changes in the essential conditions defined in the model.

\section{THE NURSING HEALTH CARE PARTNERSHIP WITHIN THE COMMUNITY COMPETENCE MODEL}

Commitment was defined as the community members' willingness to invest time and energy into maintenance of the community, awareness of their own significant role in the community, and recognition that participation in community life yields positive results (Cottrell, 1976). From the outset, it was clear that the Romanian nurses did not have a strong sense of role definition. Given the varying educational preparation modalities during the past 20 years and the broad range of positions to which medical assistants are assigned, this is understandable. In fact, the varying educational approaches have served to divide the nursing community. Without role definition the Romanian nurses have been unable to develop an awareness of their role as members of the health care community. This is compounded by the strict hierarchical structure among hospital staffs.

Self-other awareness and clarity of situational definitions were defined as the extent to which components of the community understand their own identity and interests and the ways in which these interests relate to those of other groups within the community (Cottrell, 1976). The subject of identity in the collective and individual sense is problematic for Romanian nurses. The term medical assistant (as opposed to nurse) is used in Romania. However, a medical assistant is a collective term for laboratory technicians, radiology technicians, public health field workers, research assistants, and nurses. Although the Romanian Nurses Association (RNA) supports use of the term nurse, there is internal and external resistance to the use of the term. Despite these factors, there is an emerging generation of Romanian nurses who recognize that through collective solidarity they have the potential to effect change. This growing group has invested their time and energy in developing a sense of community among Cluj-Napoca nurses.

Articulateness refers to the ability of groups within the community to articulate their positions and interests and the relation between their interests and those of other groups within the community (Cottrell, 1976). The Romanian nurses clearly articulate a tradition of strict hierarchy within the medical profession and between physicians and the other health care professionals. Medical assistants are perceived by self and other members of the health care professional community as low on the hierarchical pyramid. The hierarchical structure coupled with socialist indoctrination have perpetuated a social and professional context wherein individuals and groups are accustomed to being told what to do, how to do it, and when to do it. After acknowledging their position, nurses stated that they want to improve their condition and know that they must change. Although ar- 
ticulating the need and desire for change, the nurses also expressed the difficulty they experience in sharing with others when individuals and groups are insecure in their unstable nation and feel threatened by change. The low status of nursing generates feelings of powerlessness among nurses and fosters low priority for nurses as they compete for the limited pool of resources needed to support change and develop professional status.

Communication is the ability of the community to establish common meanings and to effectively send and listen to messages (Cottrell, 1976). The channels of communication among themselves and with physicians and patients were limited for Romanian nurses. As mentioned previously, they felt powerless, and therefore did not communicate in a closed system unwilling to listen. In Cluj-Napoca there are presently several mechanisms for nurses to establish common meanings and to begin to develop the necessary skills to effectively send and listen to messages, including two nursing unions (Sanitas and ProSana) and the RNA with a local chapter in Cluj-Napoca. An area of strength, related to the community competence component of communication, is the president of the national RNA, who has excellent communication skills and a forward vision of nursing in Romania. Unfortunately, she is housed in the capital of Romania and modes of communication are poor and costly.

Conflict containment and accommodation involves the recognition of conflict in a community and the presence of procedures to ensure that conflict is accommodated in such a way that communication channels remain open (Cottrell, 1976). The health care system in Romania has been in a developing stage since the revolution but still remains in disarray. Partly related to this disarray and insecurity, conflict exists in many areas of the health (nursing and medical) community. There is conflict between the nurses of Cluj-Napoca and the chief nurse. Conflict exists between the two nursing unions. The Sanitas union is made up primarily of older nurses, whereas the ProSana union is made up primarily of younger nurses. There is conflict between physicians and nurses. Physicians are accustomed to being in a powerful position in the health care environment and are not accustomed to working with nurses as colleagues. The Romanian nurses recognize that these conflicts exist but do not have the skills or confidence to effectively deal with the situations.

Participation is defined as the community contributing to defining and implementing goals and projects (Cottrell, 1976). Many of the Romanian nurses welcomed the project and were openly willing and excited about participating. However, their participation initially included showing us their workplaces and the nursing unions organizations. They looked to the U.S. nurses to define the goals of the project and to "tell us what you can do for us." They asked many questions about the U.S. health care system, nursing roles, and educational systems. They were unwilling to accept that the U.S. system was anything less than perfect. They wanted the U.S. nursing team to provide the answers to their problems. With the leadership of one of the younger nurses (a graduate of a post-high-school 3-year nursing program), the Romanian nurses became more involved in participating in one of the project activities, the first nursing conference. 
Management of relations with larger society was defined as understanding and adapting to the larger social system. It involves effectively using experts and resources that the larger social system has to offer (Cottrell, 1976). The health care system in Romania continues to be very unstable and is constantly changing. Therefore, it is difficult to understand or adapt to the larger health care system. All people in Romania are expending their energies in adapting to a new post-1989 revolution social, political, and economic environment. The experts and resources are unclear. In the 3 months between our initial and second visits, we saw the health care structure and leadership in Cluj-Napoca dramatically change.

Machinery for facilitating participant interaction and decision making involves the presence of procedures and structure for involving community members in the decision-making process (Cottrell, 1976). A beginning structure for facilitating nursing interaction and decision making existed but it is highly underdeveloped at present. The nursing unions and the nursing organization are neophyte organizations struggling for an identity and a voice. The two nursing unions both have offices and a skeleton administrative structure with a fairly large membership. Similarly, the local nursing association has a president but a smaller membership. The RNA has a publication entitled Jurnal de Nursing for its membership. However, mission statements, goals, and objectives of the association and a structured plan of association activities are not in place.

The chief nurse and president of the local chapter of the RNA recognized the need for procedures and structure related to both the nursing organization and nursing activities in general. For example, she asked the U.S. nurses to provide her with samples of nursing practice standards, nurse practice acts, documentation styles for nursing notes, and other nursing procedures and policies.

Leadership or developing leadership qualities, a dimension added to Cottrell's (1976) eight conditions by Minkler and Wallerstein (1997), was an important aspect of this project. The U.S. nursing team viewed the partnership nurses as potential leaders. However, the Romanian nurses did not view themselves as leaders. Due to the social and political system, the educational system, and nursing practice conditions, low self-esteem and low professional image of nurses were evident. Emerging leaders are against the collective mindset of the "follow the herd, don't think for yourself" mentality of the prerevolution days. Leaders definitely existed among the Romanian nurse partners and their nurse cohorts. Unfortunately, they were unaware of the leadership characteristics that they exhibited or how to utilize them.

One young nurse in Cluj-Napoca emerged as a strong leader and served as an excellent liaison between the Romanian and U.S. nurse partners. She also served as a role model to the Romanian nurses. Initially, the Romanian nurses asked the U.S. nurses to completely plan an upcoming nursing conference. After the emergence of the Romanian nurse leader, the nursing conference was planned jointly by the nurse partners.

To enhance the eight community competence conditions, and thus empower the nurses as valued professionals, activities to improve self-esteem and the knowledge 
base of the Romanian nurses were initiated. These activities included trust building, mentorship, role modeling, and educational sessions.

Trust building was an essential element. The U.S. nurses used multiple methods of open communication. We related to the Romanian nurses as colleagues in a respectful, open manner. We provided appropriate positive feedback to the nurses about their roles and activities. We answered all questions in a frank and open manner. We consistently followed through in providing information requested by any of the partners.

Mentorship and role modeling occurred in many ways. The Romanian nurses saw us relate to physicians and administrators in a collegial, strong, and productive manner. We exhibited assertiveness skills. Team-building skills were demonstrated at various group meetings that were held with nurses and other disciplines. They saw the U.S. nurses take leadership roles (e.g., set agendas, develop proposals, lead meetings) and negotiate with physicians and administrators. The Romanian nurses were able to observe four U.S. nurses who were competent members of the health care team and who felt a strong sense of self-esteem and a high esteem for nurses in general. Ultimately, a more structured educational format developed with the first annual nursing conference in Cluj-Napoca, consisting of several educational and networking sessions.

\section{DISCUSSION}

An outcome of the project was the development and occurrence of the first nursing conference in the city of Cluj-Napoca, Romania, held in conjunction with an annual medical conference. Nurses in Cluj-Napoca, with the support of the U.S. nursing team, organized the conference. Both the Cluj-Napoca nurses and the U.S. nurses presented papers that provided a sense of accomplishment and increased the perceived status of the Romanian nurses. In addition, two of the U.S. nurses presented papers at the medical conference. This was the first occasion on which nurses were invited to deliver scholarly papers at a medical conference in Romania.

The conditions of the community competence model that improved the most among the Cluj-Napoca partner community nurses were commitment, self-other awareness, articulateness, participation, and leadership. The Romanian-U.S. nurse partnership allowed an interaction among the two groups with the Romanian nurses in Cluj-Napoca gaining a clearer idea of nursing as a profession. Through the project and especially through the nursing conference, the Romanian nurses became more articulate, were able to communicate their specialty areas to their peers, and became more aware of themselves as leaders who participated in the development and implementation of their first nursing conference.

The specific goals of the nursing component of this multidisciplinary, international health care partnership were accomplished during this project. The competency of the Romanian nurses in the clinical setting and the increased interaction between physicians 
and nurses could not be directly measured in the short duration of the project. However, the community competence model demonstrated that the Romanian nurses emerged with a more positive image of nursing and self, a set of attitudes and skills that they could implement in their clinical settings and in interactions with other health care professionals.

Because the number of actual visits and interactions may be limited, the community competence model serves as a guide to enhance collaborative activities. The model can assist in directing the activities and interventions that increase competence in the defined conditions or can serve to strengthen areas already seen as assets. The community competence model also can serve as a summative or outcome evaluation of the project as demonstrated with this international project.

\section{REFERENCES}

Angiewich, E. (1996). Cluj-Napoca. In Review Romania, 8(2), 30-31.

Boscom, K. (1991). Romania's nursing crisis. Journal of Christian Nursing, 8, 24-29.

Cottrell, L. S. (1976). The competent community. In B. H. Kaplan, R. N. Wilson, \& A. H. Leighton (Eds.), Further explorations in social psychiatry (pp. 21-43). New York: Basic Books.

Denham, A., Quinn, S. C., \& Gamble, D. (1998). Community organizing for health promotion in the rural South: An exploration of community competence. Family and Community Health, 21, 1-21.

Eng, E., \& Parker, E. (1994). Measuring community competence in the Mississippi Delta: The interface between program evaluation and empowerment. Health Education Quarterly, 21, 199-220.

Goeppinger, J., \& Baglioni, A. J. (1985). Community competence: A positive approach to needs assessment. American Journal of Community Psychology, 13, 507-523.

Goeppinger, J., Lassiter, P. G., \& Wilcox, B. (1982). Community health is community competence. Nursing Outlook, 30, 464-467.

Lakey, C. K., Nicholas, P. K., Wolf, K. A., \& D'Meza Leuner, J. (1996). Health care and nursing in Romania. Journal of Advanced Nursing, 23, 1045-1049.

Minkler, M., \& Wallerstein, N. (1997). Improving health through community organization and community building. In K. Glanz, F. M. Lewis, \& B. Rimer (Eds.), Health behavior and health education: Theory, research and practice (2nd ed., pp. 212-235). San Francisco: Jossey-Bass.

Ross, J. (1997). Toward a healthier workplace in Romania. Common Health, 12(8), 20-22.

World Bank. (1992). Romania: Human resources and the transition to a market economy. Washington, DC: Author.

World Bank. (1998). Romania. Washington, DC: Author.

World Health Organization. (1996). World health statistics annual. Geneva, Switzerland: Author. 